\title{
Effect of the Tank Design on the Flow Pattern Generated with a Pitched Blade Turbine
}

\author{
M. Ammar, Z. Driss", W. Chtourou, M. S. Abid \\ National Engineering School of Sfax (ENIS), Laboratory of Electro-Mechanic Systems (LASEM), \\ University of Sfax, B.P. 1173, km 3.5 Road Soukra, 3038, Sfax, Tunisia
}

\begin{abstract}
The effect of the tank design on the hydrodynamic structure is carried out in three tanks; cylindrical tank, curved tank and spherical tank; equipped with a six-pitched blade turbine (PBT6). The hydrodynamic behaviour is numerically predicted by the resolution of the Navier-Stokes equations in conjunction with the Renormalization Group (RNG) of the $\mathrm{k}-\varepsilon$ turbulence model. These equations are solved by a control volume discretization method. The numerical results from the application of the CFD code "Fluent" with the Multi Reference Frame (MRF) model are presented in the impeller stream region. Particularly, the velocity components and the turbulent characteristics are presented in different planes containing the blade. The power consumption of these stirred tanks was calculated to choose the most effective system. The comparison between the numerical results and the experimental data showed a good agreement.
\end{abstract}

Keywords CFD, MRF, Turbulence, Design Tank, PBT turbine

\section{Introduction}

Stirred tanks have wide applications in different industrial process. In the various applications, stirred tanks are required to fulfill several needs like blending of miscible liquids, dispersion of gases or immiscible liquids into a liquid phase, suspension of solid particles, heat and mass transfer promotion and chemical reactions. The study of the hydrodynamic structure generated in stirred vessels is interesting to improve the performances of the agitators and the vessels by the development of the geometrical and operational conditions[1-3]. In the literature, the study of the hydrodynamic structure generated with a pitched blade turbine (PBT) was initiated in several experimental and numerical works on the discharge zone. For example, we can cite the experimental works of Nagata[4], Suzukawa et al.[5], Karcz et al.[6], Dan Taca et al.[7], Armenante et al.[8], and Aubin et al.[9]. In his experimental study, Nagata[4] studied the effect of the pitched blades on the power number with two pitched blades turbine (PBT2). Using a LDA system, Suzukawa et al.[5] studied the effect of the pitched blades in a baffled stirred tank equipped with a four pitched blade turbine (PBT4). Karcz et al.[6] studied the influence of the baffles on the variation of the power number with a three pitched blades turbine (PBT3). Moreover, Armenante et al.[8] studied the hydrodynamic structure of the turbulent flow generated with a six pitched blades turbine (PBT6) is investigated for two

* Corresponding author:

zied.driss@enis.rnu.tn (Z. Driss)

Published online at http://journal.sapub.org/mechanics

Copyright (C) 2012 Scientific \& Academic Publishing. All Rights Reserved different Reynolds numbers. Armenante et al.[8] presented the velocity profiles and the turbulent kinetic energy distribution of a flow generated by a 6-blade, 45, PBT in an unbaffled, flat-bottom, cylindrical tank provided with a lid, and completely filled with water. The mean and fluctuating velocities in all three directions were experimentally measured with a laser doppler velocimeter (LDV) at five different heights and twenty radial positions within the vessel. Aubin et al.[9] studied the baffled tank equipped with a PBT6 turbine. Particularly, they investigated the influence of the numerical approach, the discretization schema and the turbulence models on the numerical results. Dan Taca and Paunescu[7] have used a spherical tank for the suspension of solid particles in the reactors. They compared the influence of the tank shape on the power number evolution. Kchaou et al.[10] compared the effect of the flat-blade turbine with $45^{\circ}$ and $-45^{\circ}$ pitched blade turbines on the hydrodynamic structure of the stirred tank. Driss et al.[11] developed a computational study of the pitched blade turbines design effect on the stirred tank flow characteristics. Particularly, they studied the effects of different inclined angle, equal to $45^{\circ}, 60^{\circ}$ and $75^{\circ}$, on the local and global flow characteristics. To do this, a specific computational fluid dynamics (CFD) code is developed to predict the turbulent flow field. The computer method permits the numerical analyses of turbines with complex geometries. Murthy et al.[12] have used five impeller designs. The tank was fully baffled, and the flow regime was turbulent. Their objective was to carry out a detailed investigation of the predictive capabilities of the various turbulence models: the standard $\mathrm{k}-\varepsilon$ model, the Reynolds stress model (RSM) and the large eddy simulations (LES). The simulated values of the radial, tangential and 
axial velocity and the turbulent kinetic energy have been compared with the measured LDV data. Whereas, RSM and standard k- $\varepsilon$ models under-predict the turbulent kinetic energy profiles significantly in the impeller region. RSM can capture all the mean flow characteristics and the standard k- $\varepsilon$ model fails to simulate the mean flow associated with the strong swirl. Vakili et al.[13] studied the effect of different geometric parameters in stirred vessels equipped with two blades impeller (FBT2). They employed steady-state approach MRF and standard k- $\varepsilon$ turbulence model in their parametric study. Therefore, Delafosse et al.[14] have been interested to assess the ability of computational fluid dynamics (CFD) to represent the trailing vortices and their relationship with turbulence properties. For this, two simulations have been realized: an unsteady Reynolds-Averaged Navier-Stokes simulation (URANS) and a Large Eddy Simulation (LES). The trajectory of the trailing vortices predicted by the simulations has been compared with previous works. This comparison shows that the URANS simulation does not predict properly the trailing vortices while the LES results are very close to the experimental ones.

View the lack of the numerical results to predict the effect of the tank design on the hydrodynamic behavior with a PBT6 turbine, we focus on three different systems characterized by cylindrical, curved and spherical tanks. Particularly, we present the evolution of the velocity fields and the turbulent characteristics in different planes. Also, we calculate the power number in each stirred tanks.

\section{Stirred Vessels Configuration}

In this paper, we have studied the effect of the tank design on the turbulent flow pattern. Three types of tank; a cylindrical tank, a curved tank and a spherical tank; have been equipped with a pitched blade turbine (PBT6). The first system configuration is similar to Armenante et al.[8] application (Figure 1.a). This configuration is characterized by a cylindrical tank equipped with a six pitched blade turbine PBT6. The inclined angle of the blade is equal to $\beta=45^{\circ}$. This turbine have a diameter equal to $d=D / 3$ and is placed in an axial position equal to $z=H / 4$. The tank diameter $D$ is equal to its height $H(D=H)$.

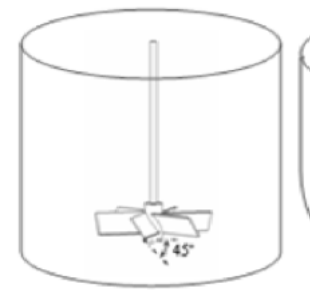

a. Cylindrical tank

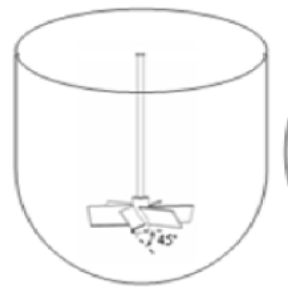

b. Curved tank

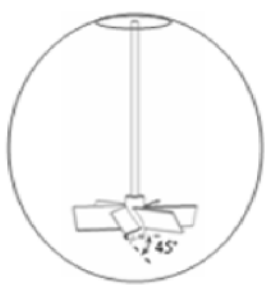

c. Spherical tank
Figure 1. Stirred tanks configurations

\section{Numerical Model}

The CFD code "Fluent" is used for numerical simulation of hydrodynamic structure of turbulent flows in a stirred tank. This code is based on solving Navier-Stokes equations with a finite volume discretization method described in detail by Patankar[15]. This technique consists in dividing the computational domain into elementary volumes around each node in the grid; it ensures the flow continuity between nodes. The spatial discretization is obtained by following a procedure for tetrahedral interpolation scheme. As for the temporal discretization, the implicit formulation is adopted. The transport equation is integrated over the control volume. The algorithm SIMPLE is used for pressure velocity coupling. To model the geometry of the impeller exactly, a 3D simulation is performed. The Multi Reference Frame (MRF) approach is available to incorporate the motion of the impeller in the stirred tank. This steady-state approach allows modelling the baffled stirred tanks and the tanks with other complex internals. It's recommended for simulation by the several searchers like Armenante et al.[8], Vakili et al.[13], Luo et al.[16], Akiti and Armenante[17] and Deglon and Meyer[18]. The grid used for the MRF solution should have a perfect surface of revolution surrounding each rotating frame. The rotating frame is used for the region containing the rotating components while a stationary frame is used for the stationary regions. The momentum equations, inside the rotating frame, are solved in the frame of the enclosed impeller while the rotating frame is solved in the stationary frame. A steady transfer of information is made at the MRF interface as the solution progresses.

\subsection{Governing Equations}

The equations to be solved are the continuity and momentum equations. The continuity equation is a statement of conservation of mass for a constant density fluid, it takes the form:

$$
\operatorname{div} \vec{v}=0
$$

The momentum equations are a statement of conservation of momentum in each of the three components. The three momentum equations are collectively called the $\mathrm{Na}-$ vier-Stokes equations. In addition to momentum transport by convection and diffusion, several momentum sources are also involved. The momentum equations take the form:

$$
\frac{\partial\left(\rho u_{i}\right)}{\partial t}+\operatorname{div}\left(\rho u u_{i}\right)-\rho \frac{u_{i}^{2}}{x_{i}}=-\frac{\partial p}{\partial x_{i}}+\operatorname{div}\left(\tau_{i}\right)-\frac{\tau_{i i}}{x_{i}}+F_{i}
$$

The total pressure $\mathrm{p}$ is defined by the following equation:

$$
p=p_{s}+\frac{2}{3} \rho k
$$

The k- $\varepsilon$ model is one of a family of two-equation models, for which two additional transport equations must be solved in order to compute the Reynolds stresses. The RNG $k-\varepsilon$ model was developed in response to the empirical nature of the standard $k-\varepsilon$ model. Rather than being based on observed fluid behavior, it is derived using statistical methods used in the field of renormalization group (RNG) theory. It is similar in form to the standard $k-\varepsilon$ model, but it contains modifica- 
tions in the dissipation equation to better describe flows with regions of high strain. In addition, a differential equation is solved for the turbulent viscosity. This model is used by several authors such as Montante et al.[19], Jaworski and Zakrazewska[20], Launder[21], Orszag and Yakhot[22] and Kelly and Gigas[23].

The equation of the turbulent kinetic energy is given in the following form:

$$
\frac{\partial(\rho k)}{\partial t}+\operatorname{div}(\rho u k)=\operatorname{div}\left[\frac{\mu_{e}}{\sigma_{k}} \operatorname{grad} k\right]+G_{k}-\rho \varepsilon
$$

The equation of the dissipation rate of the turbulent kinetic energy is written as follow:

$$
\frac{\partial(\rho \varepsilon)}{\partial t}+\operatorname{div}(\rho u \varepsilon)=\operatorname{div}\left[\frac{\mu_{e}}{\sigma_{\varepsilon}} \operatorname{grad} \varepsilon\right]+C_{1 \varepsilon} \frac{\varepsilon}{k} G_{k}-C_{2 \varepsilon}^{*} \rho \frac{\varepsilon^{2}}{k}(5)
$$

$G_{k}$ is the turbulent kinetic energy production term:

$$
G_{k}=\frac{\tau_{i j} \tau_{i j}}{2 \mu_{e}}
$$

The effective viscosity is defined as follow:

$$
\mu_{e}=1+\mu_{t}
$$

Where, $\mu_{\mathrm{t}}$ is the turbulent viscosity defined as follow:

$$
\mu_{t}=C_{\mu} \rho \frac{k^{2}}{\varepsilon}
$$

\subsection{Power Dissipation}

The knowledge of the power consumption is very important for the choice of the system installed. The power consumption depends on all parameters characterizing the external geometry of the tank, the geometry of the agitator, the flow regime and the rotating speed of the mobile. The power number $\mathrm{Np}$ allows to extrapolate calculations of the power when the diameter of the agitator $\mathrm{d}$ and its rotational speed $\mathrm{N}$ change. The power number is defined as follow:

$$
N_{p}=\frac{P}{\rho N^{3} d^{5}}
$$

$\mathrm{P}$ is the power consumption of the agitator system, given by:

$$
P=2 \pi N C
$$

Where, $\mathrm{C}$ is the torque of the agitator system.

\section{Numerical Results}

The numerical results are presented in the entire tank. Using the MRF steady-state approach, the distribution of the velocity fields and the turbulence characteristics have been introduced in the vertical and horizontal planes containing the blade. The turbulent flow is defined by a Reynolds number $R e=71000$. Due to the symmetry of the system, the computational domain is reduced to $60^{\circ}$, which includes one blade. At the two frontal planes defined by angular positions $\theta= \pm 30^{\circ}$, periodic conditions are imposed on all properties ensuring the continuity of the computational domain in the angular direction. A typical simulation is considered converged when the residual mass and other quantities characterizing the flow as the three velocity components and turbulent kinetic energy and the dissipation rate fall below 10-6 [24].

\subsection{Flow patterns in r-z plane}

Figure 2 presents the flow pattern in vertical plane containing the blade. In these tanks, it's noted that the pitched blades turbine generates a radial jet developed from the blade and propagates in the lower part of the tank. At the proximity of the sidewall, the radial jet has been transformed into two axial jets upward and downward. Also, we note the appearance of a recirculation loop located in the upper zone of the tank. At the curved bottom of the tank, a secondary recirculation loop appears just below the turbine. Beyond the area swept by the turbine, the mean velocity decreases gradually and becomes very low at the top of the cylindrical tank.

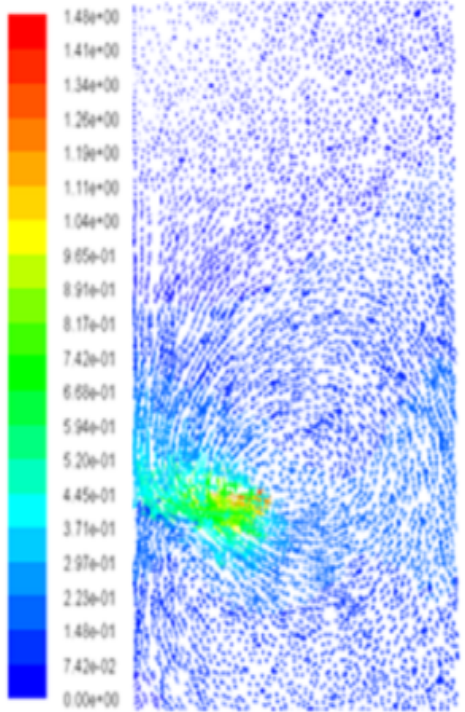

a. Cylindrical tank
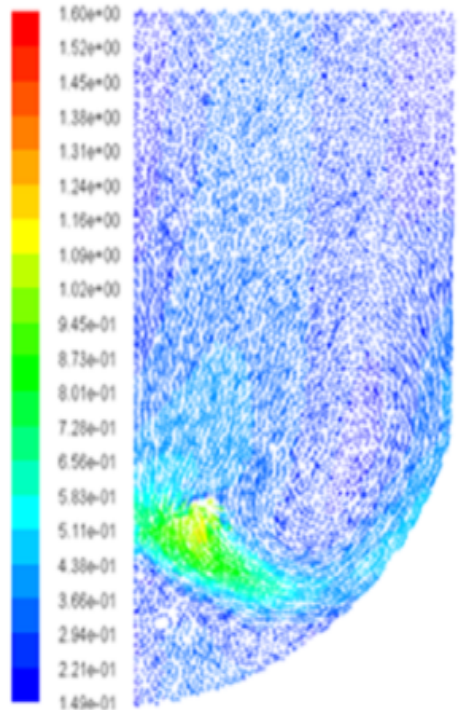

b. Curved tank

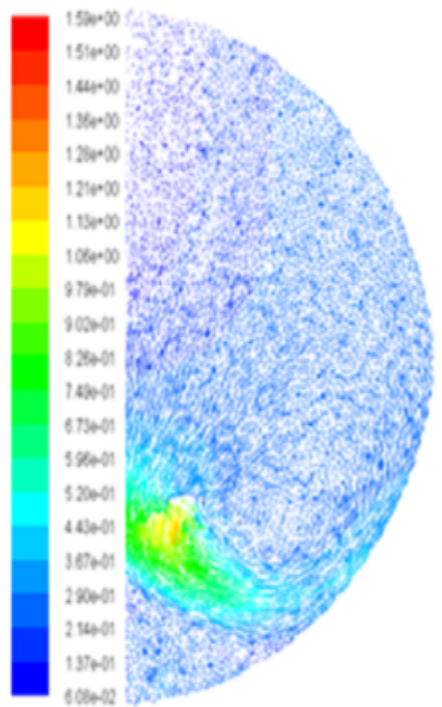

c. Spherical tank

Figure 2. Flow patterns in $r$-z plane 


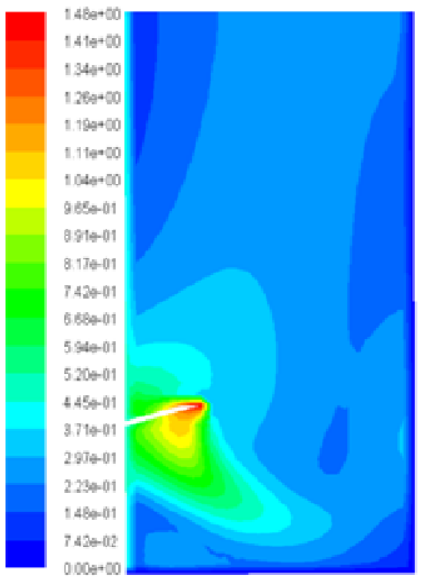

a. Cylindrical tank

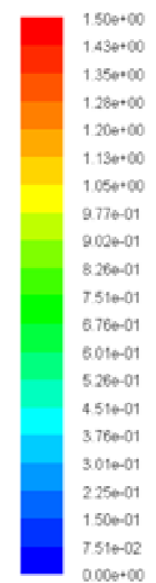

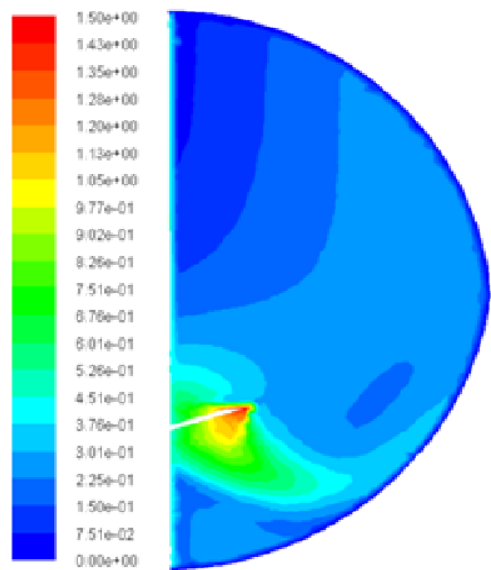

c. Spherical tank

Figure 3. Distribution of the mean velocity in $r-z$ plane

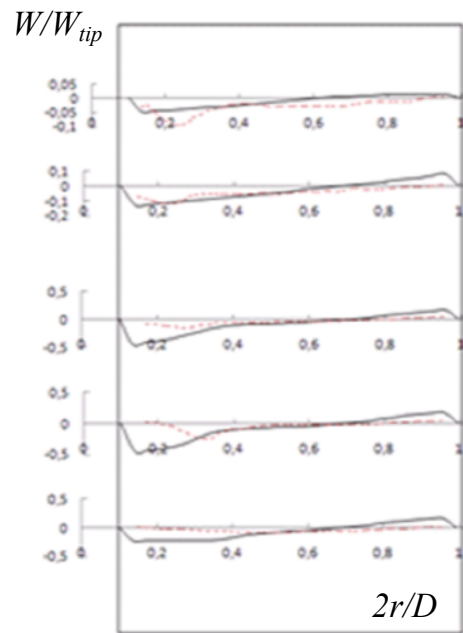

a. Cylindrical tank

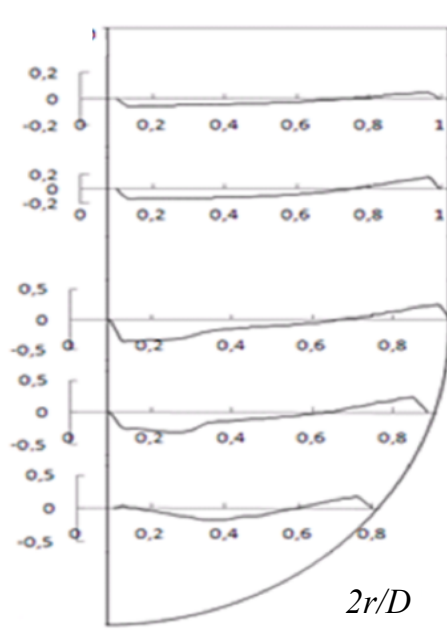

b. Curved tank

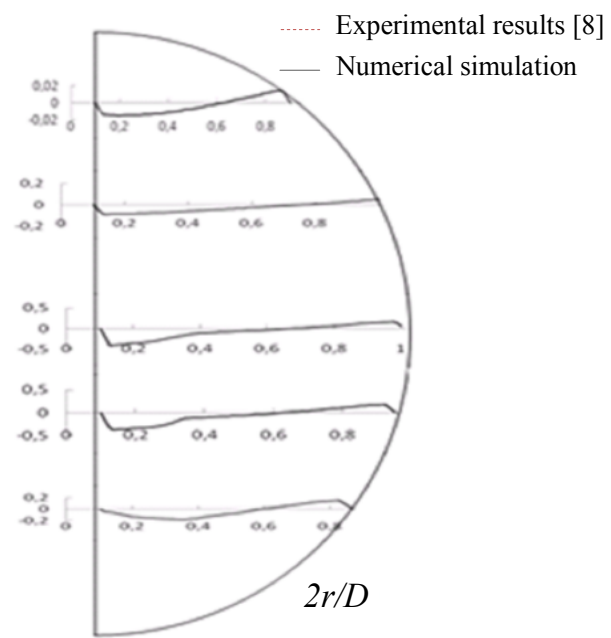

c. Spherical tank

Figure 4. Radial profiles of the axial velocity component

\subsection{Mean Velocity in r-z Plane}

Figure 3 presents the distribution of the mean velocity in the vertical plane containing the blade. Globally, it's noted that the appearance of the maximum values wake developed in the area swept by the turbine. Moreover, we find that the mean velocity decreases gradually away from the pitched blade turbine and becomes very low at the bottom and at the top of the tank. The discharge jet is more intense in the curved tank and it reaches the sidewall. The recirculation loop is more extended in the upper part of this tank and reduces the stagnant fluid zone. At the curved bottom, the second recirculation loop is appeared in the lower part of the curved tank that proves a significant fluid circulation. With a curved bottom, we observe total disappearance of the dead zones initially located at the bottom of the cylindrical tank. Contrary to the spherical tank, in the upper part the dead zones have been more developed and the recirculation loop is located near the turbine that proves the decrease of the fluid motion. Thus, we can deduce that the curved bottom reduces the stagnant areas and promotes more uniformity throughout the volume of the tank without having to modify the external geometry of the upper surface of the tank.

\subsection{Radial Profiles of the Axial Velocity Component}

Figure 4 shows the radial profiles of the axial velocity component in r-z plane containing the blade for different axial position defined by $\mathrm{z} / \mathrm{H}=0.18, \mathrm{z} / \mathrm{H}=0.24, \mathrm{z} / \mathrm{H}=0.31$, $\mathrm{z} / \mathrm{H}=0.55$ and $\mathrm{z} / \mathrm{H}=0.79$. Globally, these profiles show a great resemblance between them. The axial component vanishes at the sidewall of the tank $(2 \mathrm{r} / \mathrm{D}=1)$ and at the shaft $(2 \mathrm{r} / \mathrm{D}=0)$. Between two axial positions, these profiles follow a variation between the maximum and the minimum values. In the turbine area, these profiles present a minimum for the axial component due to the downward flow aspired by the rotation motion of the turbine. At the sidewall, these profiles reverse and reach the maximum which proves the existence of the axial upward jet. At the top of the curved tank, the axial velocity component becomes very intense. Also, at the bottom of the curved tank, the axial velocity component is very important to compare with the two other systems. So, we can deduce that the curved tank creates a largest fluid circulation. Figure 4.a shows a good agreement between our numerical results found in the case of a cylindrical tank, with experimental results found by Armenante et al.[8], which proves the validity of the numerical method adopted. 


\subsection{Axial Profiles of the Radial Velocity Components}

Figure 5 shows the axial profiles of the radial velocity component in the vertical plane containing the turbine. These profiles are presented on the height of the tank in front of the blade end. Globally, it's noted that the radial velocity component vanishes in the lower part of the curved bottom of the second and third tank. But, in the case of a cylindrical tank, the negative values shown in the lower part of the tank prove the existence of the small recirculation loop below the pitched blade turbine. The radial component is maximal in the discharge jet of the turbine. The negatives values of the radial component prove the existence of the recirculation loop just above the turbine and it vanishes in the top of each tank. We can deduce that the design of the upper part has no effect on the evolution of the radial velocity component.

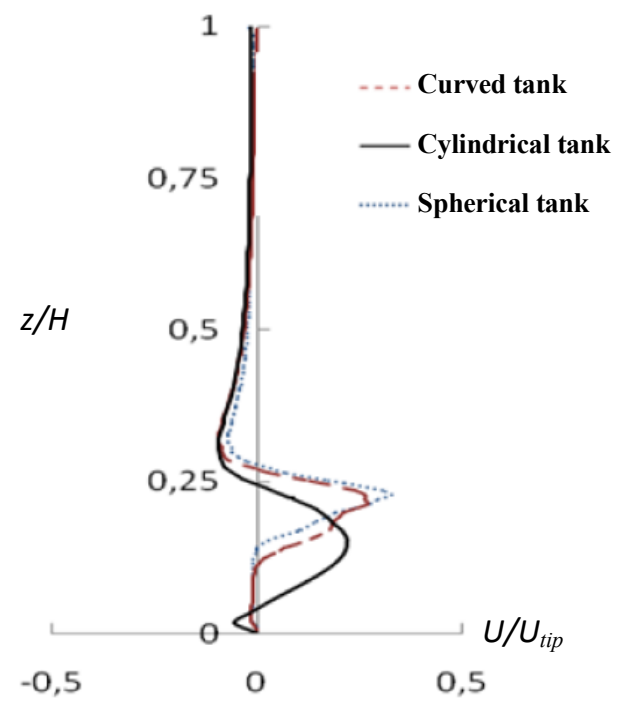

Figure 5. Axial profile of the radial velocity

\subsection{Axial Profiles of the Tangential Velocity Components}

Figure 6 presents the axial profiles of the tangential velocity component in the vertical plane containing the turbine. These profiles are presented on the height of the tank in front of the blade end. Globally, we can distinct three zones. The discharge zone characterized by a maximum values of the tangential component is located between two axial positions equal to $\mathrm{z} / \mathrm{H}=0.17$ and $\mathrm{z} / \mathrm{H}=0.34$. Below the turbine, the tangential component is very important. This fact proves the existence of a centrifugal fluid flow. Thus, the design of the bottom has a direct effect on the tangential component. With a curved bottom, the tangential component increases in the discharge area of the turbine and also in the lower area of the tank. It decreases gradually at the upper part and it vanishes in proximity of the spherical tank top surface. Then, we can deduce that the curved tank promotes more fluid circulation throughout the volume.

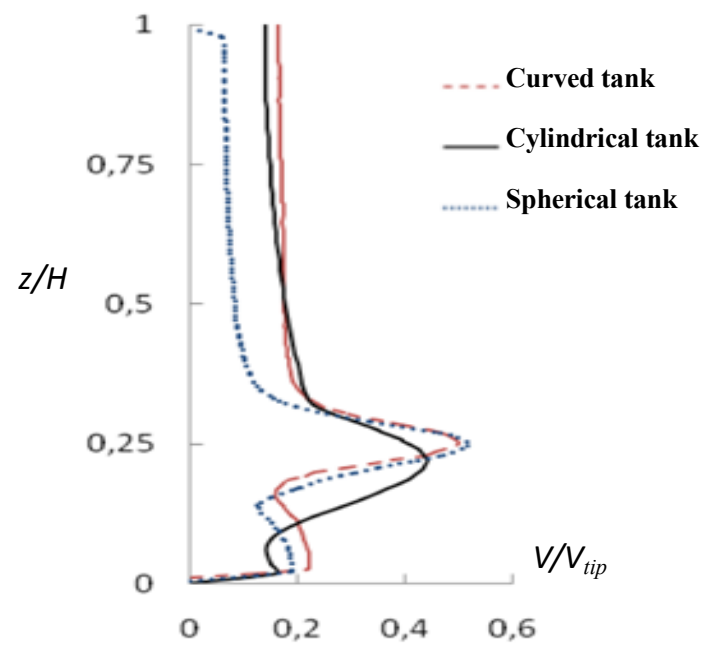

Figure 6. Axial profiles of the tangential velocity

\subsection{Turbulent Kinetic Energy in r-z Plane}

Figure 7 presents the distribution of the turbulent kinetic energy in the vertical plane containing the blade. In the each system, the wake of the maximum values of the turbulent kinetic energy appears on the mechanical source and develops within the fluid to reaches the sidewall of the tank. Also, it's noted that the turbulent kinetic energy is more extended in the case of the spherical tank.

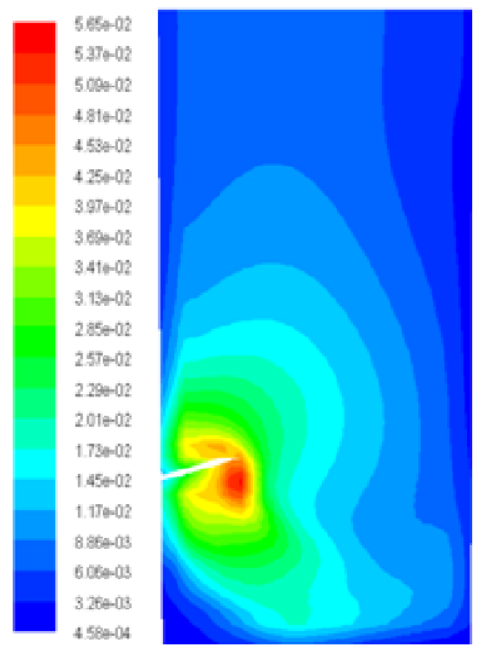

a. Cylindrical tank

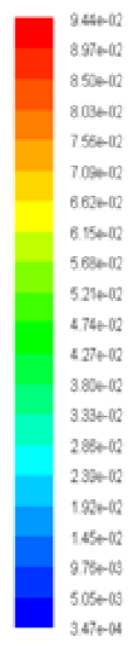

Figure 7. Distribution of the turbulent kinetic energy in $r$-z plane

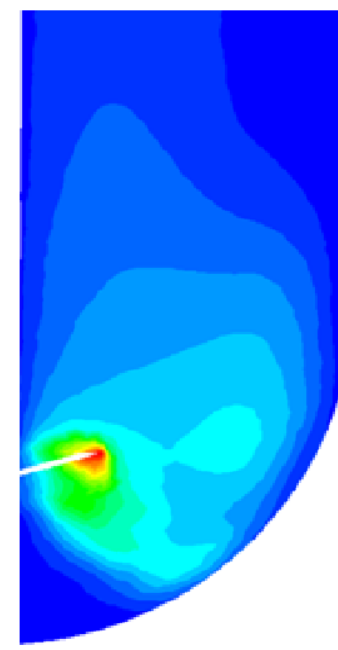

b. Curved tank
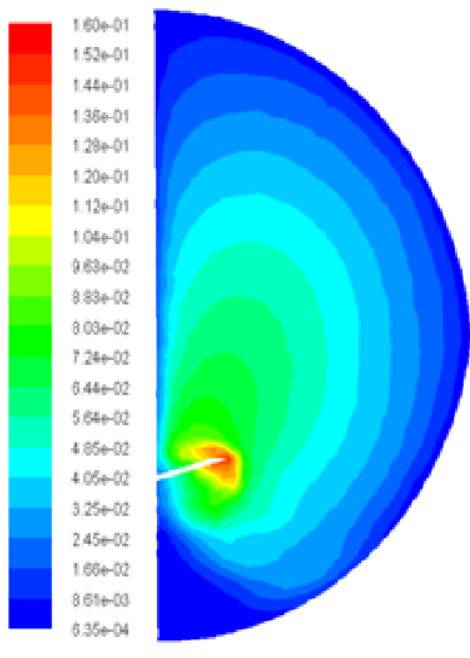

c. Spherical tank 


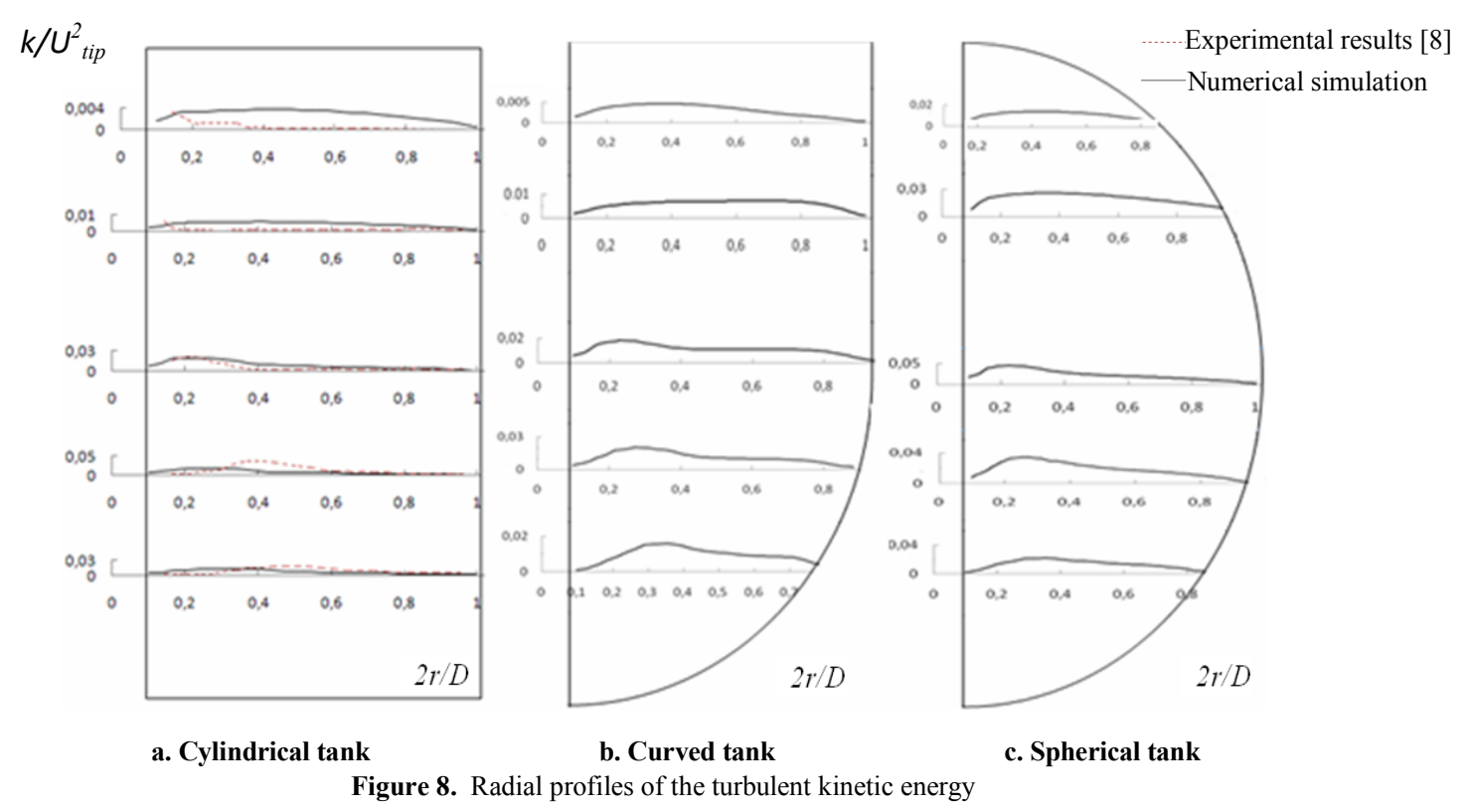

\subsection{Radial Profiles of the Turbulent Kinetic Energy}

Figure 8 shows the radial profiles of the turbulent kinetic energy in $r-z$ plane containing the blade. These profiles present the evolution of the turbulent kinetic energy in each system in different axial positions defined by $\mathrm{z} / \mathrm{H}=0.18$, $\mathrm{z} / \mathrm{H}=0.24, \mathrm{z} / \mathrm{H}=0.31, \mathrm{z} / \mathrm{H}=0.55$ and $\mathrm{z} / \mathrm{H}=0.79$. Globally, we observe a great similarity between these profiles. The turbulent kinetic energy vanishes at the sidewall of the tank $(2 \mathrm{r} / \mathrm{D}=1)$ and at the shaft $(2 \mathrm{r} / \mathrm{D}=0)$. Between these axial positions, the turbulent kinetic energy is maximal in the area swept by the PBT6 turbine and decreases gradually outside the discharge jet of the turbine. Figure 8.a shows a good agreement between our numerical results found in the case of a cylindrical tank with experimental results found by Armenante et al.[8], which proves the validity of the adopted numerical method.

\subsection{Axial Profiles of the Turbulent Kinetic Energy}

Figure 9 shows the axial profiles of the turbulent kinetic energy in the vertical plane containing the blade. According

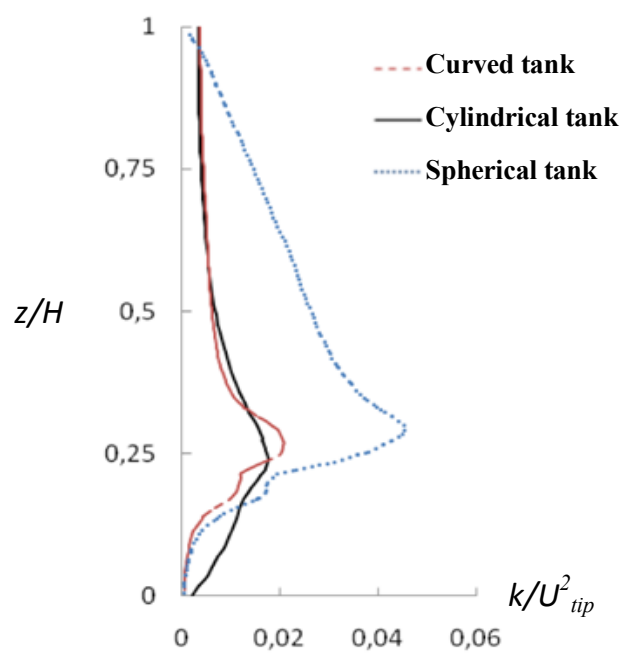

Figure 9. Axial profiles of the turbulent kinetic energy to these results, we note that the turbulent kinetic energy is maximal in the discharge jet of the PBT6 turbine and decreases rapidly beyond this zone. Particularly, in the lower part of the tank, these profiles show a great resemblance in the curved and spherical tanks because these two tanks have the same bottom design. The turbulent kinetic energy is null at the tank bottom due to the small gap between the impeller and the bottom curved. In the upper part of the tank, the turbulent kinetic energy profiles are similar in the cylindrical tank and in the curved tank because the both tanks keep the same geometry at the top. Thus, we can deduce that the design of the tank affects the evolution of the turbulent kinetic energy, and therefore the quality of the mixture. So, the tank design is a very important parameter in optimizing the mixing systems.

\subsection{Dissipation Rate of the Turbulent Kinetic Energy}

Figure 10 shows the distribution of the dissipation rate of the turbulent kinetic energy in $\mathrm{r}-\mathrm{z}$ plane containing the blade. Globally, it's noted that the dissipation rate is very low in each system. The maximum values are concentrated around the PBT6 turbine. This is explained by the transformation of the energy provided by the rotating action of the turbine as heat within the fluid.

\section{Global Characteristics}

Figure 11 presents the variation of the power number NP depending on the Reynolds number Re with a pitched blade turbine PBT6 placed respectively in the cylindrical, the curved and the spherical tank. Globally, we find that the energy dissipation defined within the fluid increases with the curved bottom of the tank. For the Reynolds numbers between $\mathrm{Re}=103$ and $\mathrm{Re}=104$, the energy dissipation defined in these three systems is very important. In fully turbulent regime, for Reynolds number between $\mathrm{Re}=104$ and $\mathrm{Re}=105$, the curved tank shows a much greater dissipation of energy. 


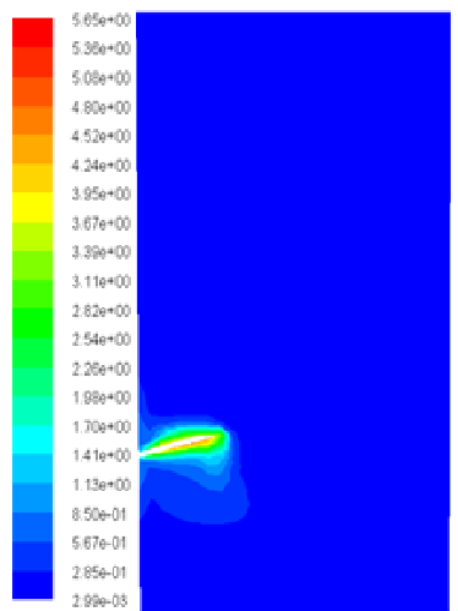

a. Cylindrical tank

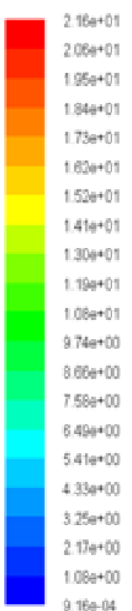

Figure 10. Distribution of the dissipation rate of the turbu

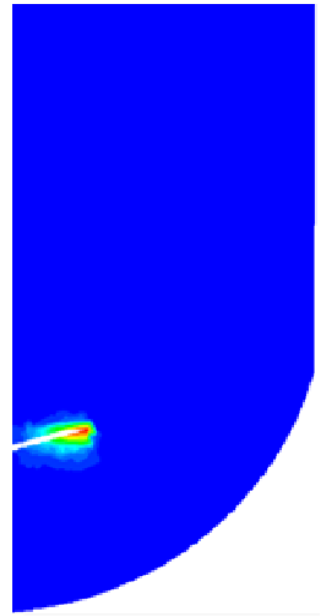

b. Curved tank
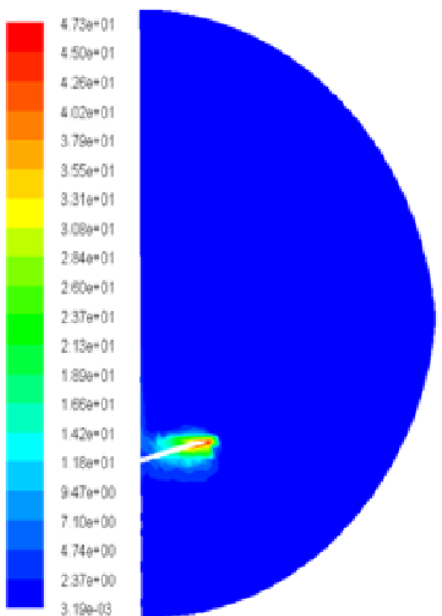

c. Spherical tank
Therefore, we can deduce that the curved tank is the best system because the presence of the curved bottom improves the quality of the mixture. So, this system consumes slightly more of the energy dissipation than the other systems.

In the case of a cylindrical tank and for the rotating speed $\Omega=450 \mathrm{rpm}$, the power number calculated with the CFD code is equal to $\mathrm{Np}=0.578$. This value is close to experimental value $\mathrm{Np}=0.670$ found in the literature by Armenante et al.[8]. This proves the validity of the numerical method adopted.

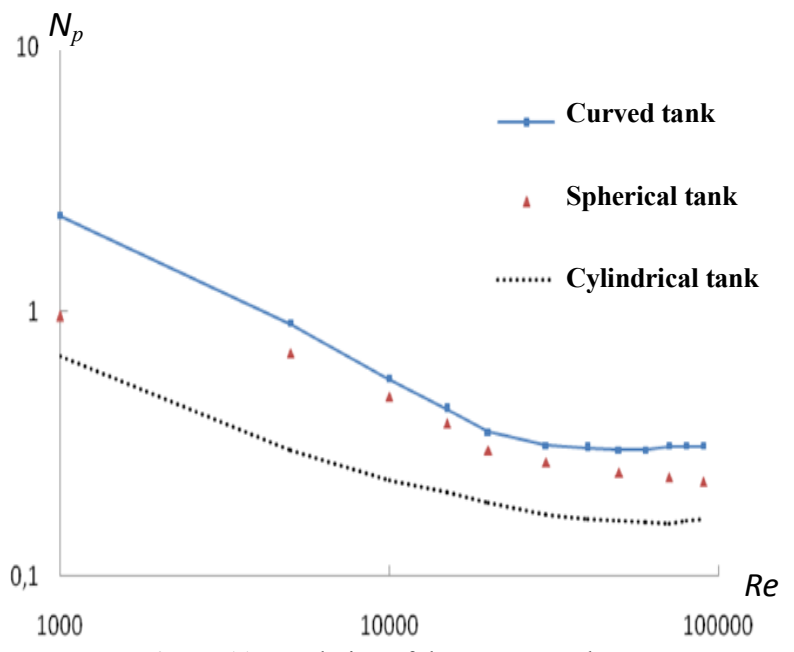

Figure 11. Evolution of the power number

\section{Conclusion}

The comparative study has been affected between three different configurations equipped with cylindrical, curved and spherical tank. Specifically, we have studied the effect of the tank design on the hydrodynamic structure of the turbulent flows generated by a six-pitched blade turbine (PBT6). The velocity components and the turbulent characteristics have been presented in different planes containing the blade. We can deduce that the use of the pitched blade turbines in the curved tank can increase the pumping action in the full tank, with slightly higher energy. In the future, we propose to characterise the hydrodynamic structure of this turbine by the particle image velocimetry (PIV) experimental technique.

\section{Nomenclature}

C: torque of the agitator system (N.m)

$C_{\mu}, C_{1 \varepsilon},{ }^{C_{2 \varepsilon}}$ : constants of the k- $\varepsilon$ model

D: diameter of the tank $(\mathrm{m})$

$\mathrm{d}$ : diameter of the impeller $(\mathrm{m})$

$\mathrm{g}$ : acceleration of gravity (m.s-2)

$\mathrm{H}$ : height of the tank (m)

$\mathrm{k}$ : turbulent kinetic energy (m2.s-2)

$\mathrm{N}$ : rotating speed of the impeller (s-1)

Np: power number

np: blade number

p: pressure $(\mathrm{Pa})$

P: power (W)

r: radial coordinate $(\mathrm{m})$

$\mathrm{R}$ : radius of the tank $(\mathrm{m})$

t: times (s)

$\mathrm{v}$ : mean velocity (m.s-1)

ui: velocity component (m.s-1)

$\mathrm{z}$ : position of the turbine in the tank (m)

G: production term of turbulence

\section{Greek Letters}

$v$ : kinetic viscosity of the fluid (m2.s-1)

$\rho$ : density of fluid (kg.m-3)

$\mu$ : dynamic viscosity of the fluide (Pa.s)

$\mu_{e}$ : effective viscosity (Pa.s)

$\mu_{t}$ : turbulent dynamic viscosity (Pa.s)

$\varepsilon:$ dissipation rate of the turbulent kinetic energy (m2.s-3)

$\theta$ : angular coordinate (rad)

$\beta$ : inclined angle $\left({ }^{\circ}\right)$

$\Omega$ : rotating speed of the impeller (rpm)

$\tau$ : contraint 
$\sigma \mathrm{k}, \sigma \varepsilon$ : constants of the $\mathrm{k}-\varepsilon$ model

\section{REFERENCES}

[1] Chtourou, W., Ammar, M., Driss, Z., and Abid, M.S., 2011, Effect of the turbulence models on Rushton turbine generated flow in a stirred vessel, Cent.Eur. J.Eng., 1(4), 380-389

[2] Ammar, M., Chtourou, W., Driss, Z., and Abid, M.S., 2011, Numerical investigation of turbulent flow generated in baffled stirred vessels equipped with three different turbines in one and two-stage system, Energy 2011, 36, 5081-5093

[3] Ammar, M., Driss, Z., Chtourou, W., and Abid, M.S., 2011, Effects of baffle length on turbulent flows generated in stirred vessels, Cent. Eur. J. Eng, 1(4), 401-412

[4] Nagata S., 1975, Mixing: principles and applications. John Wiley \& Sons: Halstead press, Japan

[5] Suzukawa, K., Mochizuki, S., and Osaka, H., 2006, Effect of the attack angle on the roll and trailing vortex structures in an agitated vessel with a paddle impeller. Chemical Engineering Science, 61, 2791-2798

[6] Karcz, J., and Kaminska-Brzoska, J., 1994, Experimental studies of the influence of the blade curvature of a disc turbine on power consumption. Chem. Proc. 15, 371-378

[7] Dan Taca, C., and Paunescu, M., 2001, Power input in closed stirred vessels. Chemical Engineering Science, 56, 4445-4450

[8] Armenante, P.M., and Chou, C.C., 1997, Velocity profiles in a baffled vessel with single or double pitched- blade turbines. A.I.ch.E. J., 42, 42-54

[9] Aubin, J., Fletcher, D. and Xuereb, C., 2004, Modelling turbulent flow in stirred tanks with CFD: the influence of the modelling approach, turbulence model and numerical schema. Experimental Thermal and Fluid Science, 28, 431- 445

[10] Kchaou, H., Driss, Z., Bouzgarrou, G., Chtourou, W., Abid M.S., 2008, Numerical investigation of internal turbulent flow generated by a flat-blade turbine and a pitched-blade turbine in a vessel tank, International Review of Mechanical Engineering, 2, 427-434

[11] Driss, Z., Bouzgarrou, G., Chtourou, W., Kchaou, H., Abid M.S., 2010, Computational studies of the pitched blade turbines design effect on the stirred tank flow characteristics, European Journal of Mechanics B/Fluids, 29, 236-245

[12] Murthy, N.B., and Joshi, J.B., 2008, Assessment of standard k- $\varepsilon$ RSM and LES turbulent models in a baffled stirred agitated by various impeller designs, Chemical Engineering Science, 63, 5468-5495

[13] Vakili, M.H., Nasir, M., and Esfaharry, 2009, CFD analus of turbulence in a baffled stirred tank, a three compartement model. Chem. Eng. Sci., 64, 351-362

[14] Delafosse, A., Morchain, J., Guiraud, P., and Liné, A., 2009, Trailing vortices generated by a Rushton turbine: Assessment of URANS and large eddy simulation. Chemical Engineering Reasearch and Design, 87, 401-411

[15] Patankar, S.V., 1980, Numerical heat transfer and fluid flow. Mc Graw Hill

[16] Luo, J.Y., Issa, R.I., and Gosman, A.D., 1994, Prediction of Impeller Induced Flows in Mixing Vessels Using Multiple Frames of Reference, IChemE Symposium Series, 136, 549-556

[17] Akiti, O., and Armenante, P.M., 2004, Experimetal ly-validat ed micromixing based CFD model for fed-batch stirred reactor, A.I.ch.E. Journal., 56(3), 566-577

[18] Deglon, D.A., and Meyer, C.J., 2006, CFD modeling of stirred tanks: Numerical considerations, Minerals Engineeing, 19, 1059-1068

[19] Montante, G., Lee, K.C., Brucato, A., and Yianneskis, M., 2001, Experiments and predictions of the transition of the flow pattern with impeller clearance in stirred tanks, Computers and Chemical Engineering, 25, 729-735

[20] Jaworski, Z. and Zakrazewska, B., 2002, Modeling of the turbulent wall jet generated by a pitched blade turbine impeller, The effect of turbulence model, Trans Ichem. E., 8

[21] Launder, B.E., 1974, Spalding D.B. Progress in the Devepement od a Reynolds Stress turbulence closure, J. Fluid. Mech., 68(3), 537-566

[22] Orsgaz, A., Yakhot, V., 1994, Recent ideas on turbulence transport modeling, in 2nd world conference in Applied CFD, $8,1-8$

[23] Kelly, W. and Gigas, B., 2003, Using CFD to predict the behavior of power law fluids near axial-flow impellers operating in the transitional flow regime, Chemical Engineering Science, 58, 2141-2152

[24] Driss, Z., Karray, S., Kchaou, H., and Abid, M.S., 2011, Computer simulations of laminar flow generated by an anchor blade and a Maxblend impellers, Science Academy Transactions on Renewable Energy Systems Engineering and Technology, 1(3), 68-76 